\title{
Simulation of SPWM Control Method for UPS System
}

\author{
Akila Saranya \\ Adlin Jeyarani A \\ Anna University \\ Department of EEE \\ DCE, Chennai \\ @ Kannathal L \\ Anna University \\ Department of EEE \\ DCE, Chennai \\ Mohan D \\ Assistant Professor \\ Department of EEE \\ DCE, Chennai \\ Venugopal G \\ Assistant Professor \\ Department of EEE \\ DCE, Chennai \\ Manigandan S \\ Assistant Professor \\ Department of EEE \\ HITS, Hosur
}

\begin{abstract}
This paper deals with the analysis of implementing Sinusoidal Pulse Width Modulation (SPWM) controlling strategy in three phase Uninterruptible Power Supply (UPS) system operating under highly nonlinear load. The conventional type of controller is not enough to reduce harmonics in the system under highly nonlinear load in high power system. The SPWM based method is applied to the UPS system to reduce THD level at minimum value. The Simulation is done by Matlab/Simulink environment.
\end{abstract}

\section{Keywords}

SPWM, UPS, nonlinear load,THD

\section{INTRODUCTION}

Uninterruptible Power Supply (UPS) system supplies emergency power in case of utility power failures and are now-a-days widely used as backup power for critical loads such as computers and life support systems in hospitals [3]. In UPS systems, the overall performance is dependent upon the static inverter-filter arrangement which is used to convert $\mathrm{dc}$ input power to high-quality ac voltage of low total harmonic distortion (THD)[2]. The performance of the system is measured both in terms of steady-state performance, such as voltage regulation and THD, and transient performance, such as response to a sudden change in load[1],[2].

UPS have been designed with high quality output voltage for using it in medical and military equipment application. The UPS output voltages have less distortion and maintains the sinusoidal nature [1]. In the sinusoidal output voltage the power factor value is maintained nearly as unity power factor. The conventional control methods such as dead - beat control and predictive and repetitive control methods have been widely used in the UPS system. The convention methods have the implementation complexion and it is affected in the high power loads[6,8].

In SPWM method the implementation is easy, flexible and controls each phase voltage independently. By using the SPWM method in UPS system, the output voltage has fewer harmonics when compared to the conventional control method. The THD value can be reduced to $5 \%$ of the fundamental value [1][2].

\section{SYSTEM DESCRIPTION}

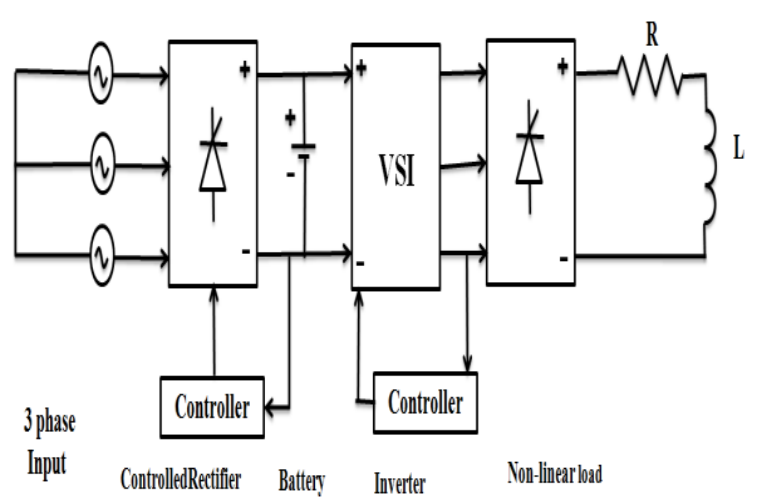

Figure 1: Block diagram for UPS system

The three phase source is supplied to the thyristor based controlled rectifier, which is to convert the fixed ac voltage to $\mathrm{dc}$ output voltage. To reduce the ripple content in the output dc voltage, filter is used in the circuit. The controlled rectifier gate pulse is generating the feedback from the dc output side and is given to the controller to produce the required gate pulse. The controlled rectifier output voltage is given to the battery. The battery is used to store the dc voltage in the circuit. The dc output voltage is given to the Voltage Source Inverter (VSI) which converts the dc voltage to ac output voltage. The ac output voltage is given to the linear and nonlinear load. The required gate pulse for Voltage Source Inverter (VSI) is produce by the SPWM circuit. The SPWM signal is obtained from the load side and given as a feedback to the control circuit to generate the gate pulse for the inverter.

\section{SIMULATION}

The simulation circuit is consists of three phase source, controlled rectifier, inverter, SPWM controller, filter, multilevel inner loop controller[9],[10],[11] and three phase nonlinear load. The simulation is done by Matlab /Simulink environment. 


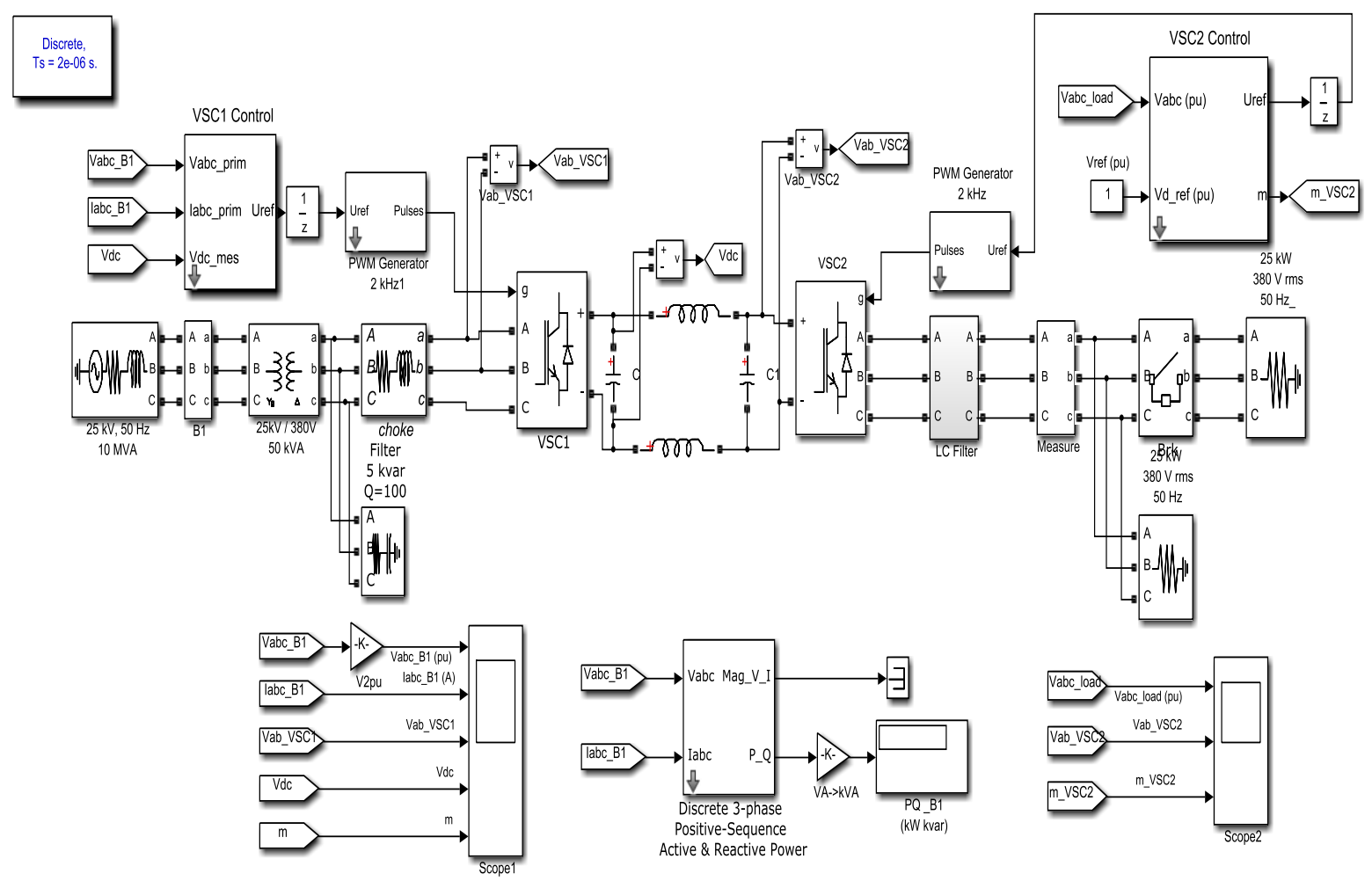

Figure 2:Simulation circuit of SPWM based UPS System

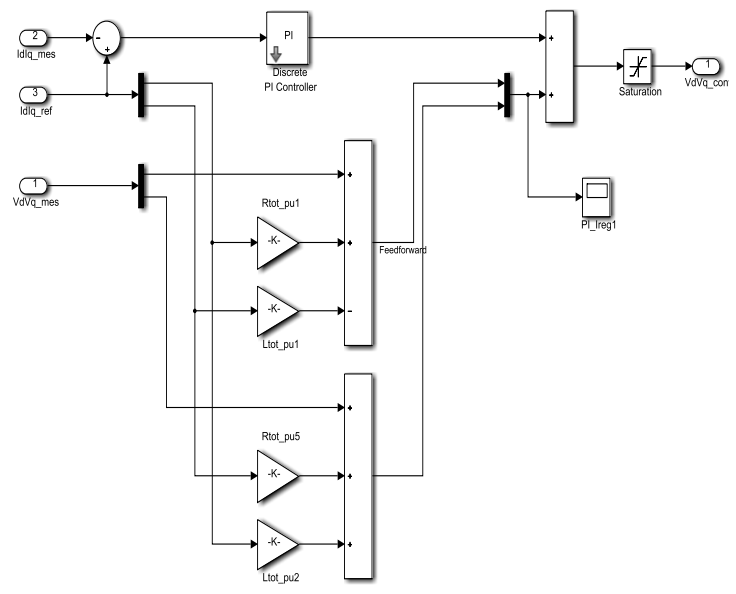

Figure 3: Inner loop PI controller

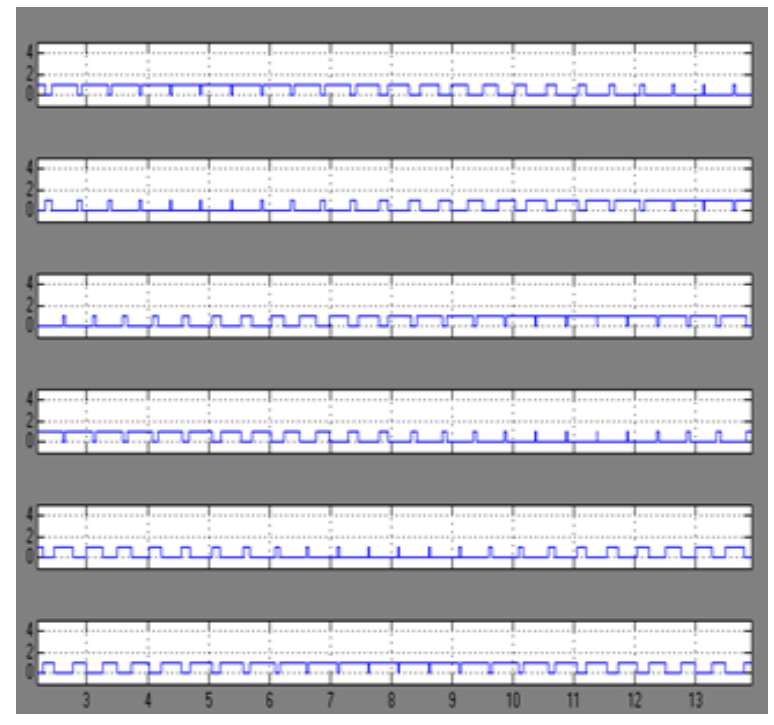

Figure 4:Gate pulse for inverter 


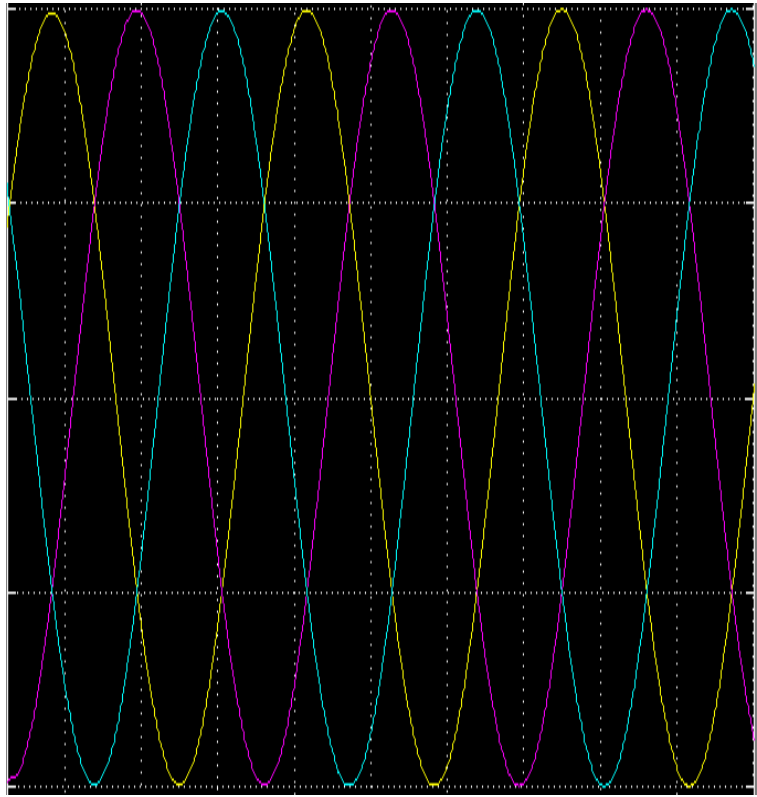

Figure 5: Output Voltage

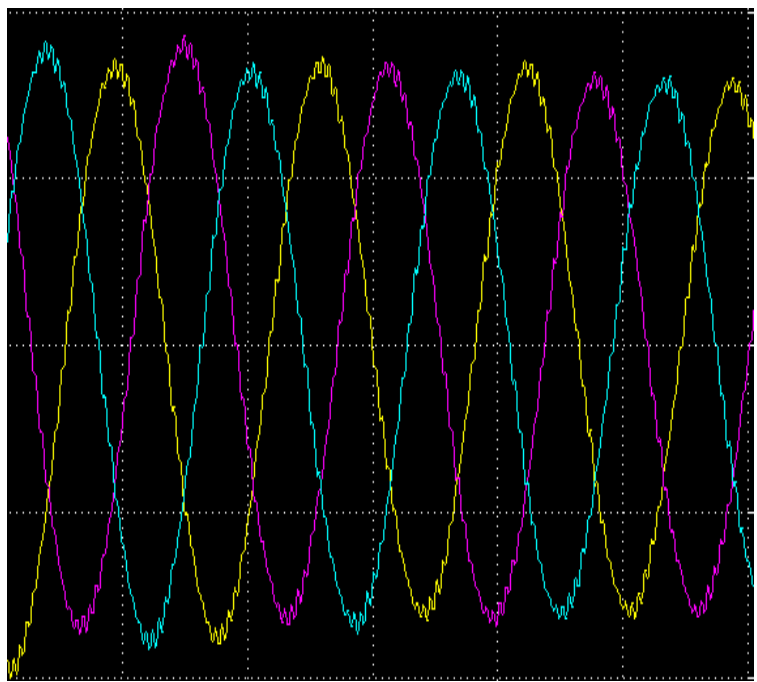

Figure 6:Output Current

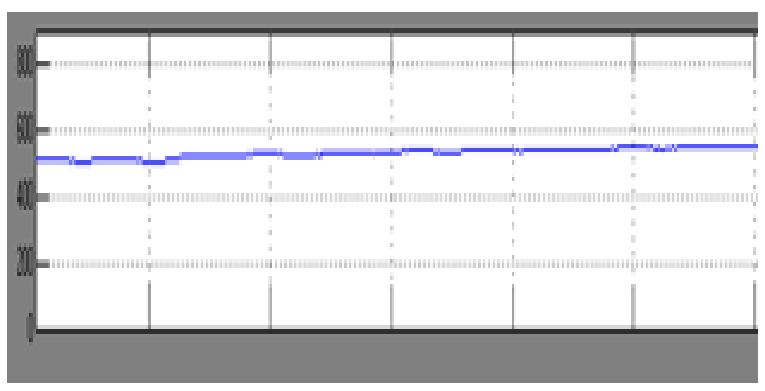

Figure 7:Battery output voltage

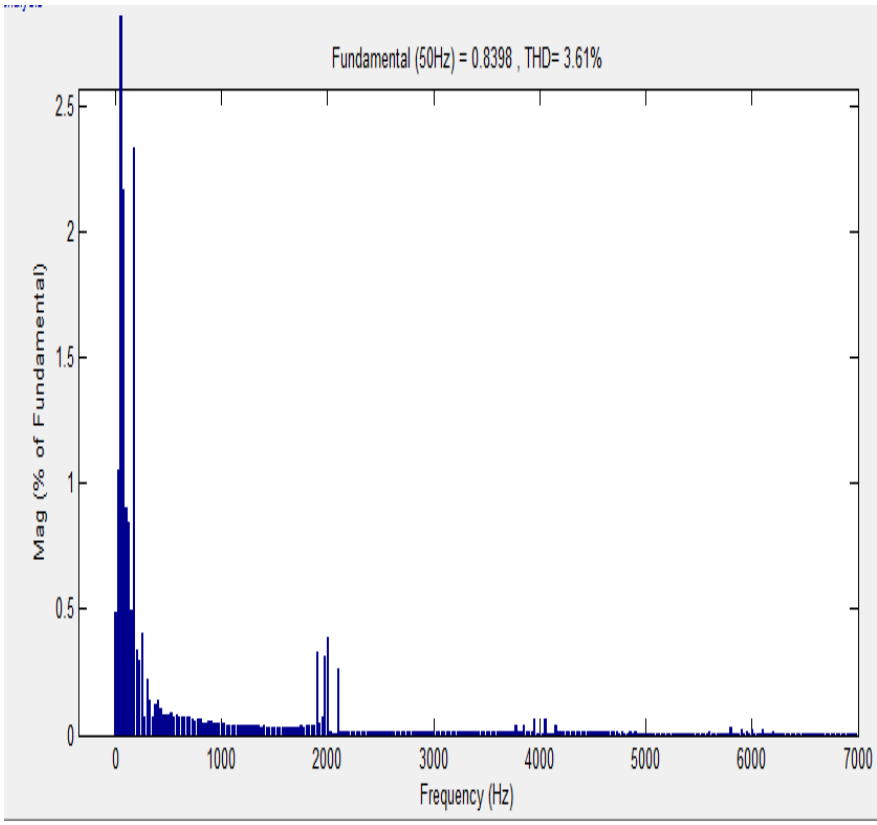

Figure 8 :\% THD of output voltage

\section{CONCLUSION}

Thus the paper presents the analysis of SPWM control strategy for UPS system with nonlinear load. The distortion of the output voltage is reduced to a minimum level. The proportional integral controller is used as the inner current loop to control the output current. The THD value is reduced up to $3.61 \%$ of the fundamental frequency. The SPWM method is used to maintain the output voltage of the UPS system in sinusoidal nature when it is connected with the nonlinear loads. By implementing the above method of controlling the efficiency of the UPS system can be increased as the harmonics and distortion are reduced.

\section{REFERENCES}

[1] BunyaminTamyurek , "A High-Performance SPWM Controller for Three-Phase UPS Systems Operating Under Highly Nonlinear Loads" IEEE Trans. On power electronics, vol. 28, no. 8, pp3689-3701 august 2013

[2] Heng Deng, Ramesh Oruganti, and DiptiSrinivasan,Senior "A Simple Control Method for High-PerformanceUPS Inverters Through Output-Impedance Reduction" IEEE Trans. on Ind electronics, vol. 55, no. 2, FEB 2008 pp 888-898.

[3] F. Botter' on and H. Pinheiro, "A three-phase UPS that complies with the standard IEC 62040-3," IEEE Trans. Ind. Electron., vol. 54, no. 4, pp. 2120-2136, Aug. 2007.

[4] S. Jiang, D. Cao, Y. Li, J. Liu, and F. Z. Peng, "Low THD, fast transient, and cost-effective synchronousframe repetitive controller for three-phase UPS inverters,"IEEETrans. Power Electron., vol. 27, no. 6, pp. 2294-3005, 2012.

[5] U. Borup, P. N. Enjeti, and F. Blaabjerg, "A new space-vector-based control method for UPS systems powering nonlinear and unbalanced loads," IEEE Trans. Industry Appl., vol. 37, no. 6, pp. 18641870, Nov./Dec. 2001. 
[6] Q.-C. Zhong, F. Blaabjerg, J. Guerrero, and T. Hornik, "Reduction of voltage harmonics for parallel-operated inverters equipped with a robust droop controller," inProc.IEEE Energy Convers.Congr.Expo.,Phoenix,AZ, 2011, pp. 473478.

[7] Q.-C. Zhong and Y. Zeng, "Can the output impedance of an inverter be designed capacitive?" inProc.37th Annu. IEEE Conf. Ind. Electron., 2011,

[8] P. Mattavelli, "Synchronous-frame harmonic control for high-performance AC power supplies,"IEEE Trans. Ind. Appl., vol. 37, no. 3, pp. 864-872,May/Jun. 2001.

[9] N. M. Abdel-Rahim and J. E. Quaicoe, "Analysis and design of a multiple feedback loop control strategy for single-phase voltage-source UPS inverters,'IEEE Trans. Power Electron., vol. 11, no. 4, pp. 532-541, Jul.1996.
[10] M. J. Ryan, W. E. Brumsickle, and R. D. Lorenz, "Control topology options for single-phase UPS inverters," IEEE Trans. Ind. Appl., vol. 33, no. 2, pp. 493-501, Mar./Apr. 1997.

[11] F. Botter' on, H. Pinheiro, H. A. Grundling, and J. R. P. H. L. Hey, "Digital voltage and current controllers for three-phase PWM inverter for UPS applications," inProc. 36th Annu. Meeting IEEE Ind. Appl., Chicago, IL, Sep./Oct. 2001, vol. 4, pp. 2667-2674.

[12] P. C. Loh, M. J. Newman, D. N. Zmood, and D. G. Holmes, "A comparative analysis of multiloop voltage regulation strategies for single and threephase UPS systems," IEEE Trans. Power Electron., vol. 18, no. 5, pp. 1176-1185, Sep. 2003.

[13] Uninterruptible power systems (UPS)-Part 3: Method of specifying the performance and test requirements,First Edition 1999-03, International Standard IEC 62040-3. 